\title{
Bone mineral density in adult coeliac disease: An updated review
}

\author{
Alfredo J. Lucendo ${ }^{1}$ and Alvaro García-Manzanares ${ }^{2}$ \\ Departments of ${ }^{I}$ Gastroenterology and ${ }^{2}$ Endocrinology and Nutrition. Hospital General de Tomelloso. Tomelloso, \\ Ciudad Real. Spain
}

\begin{abstract}
Introduction and objectives: coeliac disease (CD) affects around $1-2 \%$ of the world population. Most patients are now diagnosed when adults, suffering the consequences of an impaired bone mineralization. This review aims to provide an updated discussion on the relationship between low bone mineral density (BMD), osteopenia and osteoporosis, and CD.

Methods: a PubMed search restricted to the last 15 years was conducted. Sources cited in the results were also reviewed to identify potential sources of information.

Results: low BMD affects up to $75 \%$ of celiac patients, and can be found at any age, independently of positive serological markers and presence of digestive symptoms. The prevalence of $\mathrm{CD}$ among osteoporotic patients is also significantly increased. Two theories try to explain this origin of low BMD: Micronutrients malabsorption (including calcium and vitamin D) determined by villous atrophy has been related to secondary hyperparathyroidism and incapacity to achieve the potential bone mass peak; chronic inflammation was also related with RANKL secretion, osteoclasts activation and increased bone resorption. As a consequence, celiac patients have a risk for bone fractures that exceed $40 \%$ that of matched non-affected population. Treatment of low BMD in CD comprises gluten-free diet, calcium and vitamin D supplementation, and biphosphonates, although its effects on $\mathrm{CD}$ have not been specifically assessed.

Conclusions: up to $75 \%$ of celiac patients and $40 \%$ of that diagnosed in adulthood present a low BMD and a variable increase in the risk of bone fractures. Epidemiological changes in $\mathrm{CD}$ make bone density scans more relevant for adult coeliacs.
\end{abstract}

Key words: Coeliac disease. Osteoporosis. Osteopenia. Bone mineral density. Densitometry.

Received: $25-10-2012$

Accepted: 20-02-2013

Correspondence: Alfredo J. Lucendo. Department of Gastroenterology. Hospital General de Tomelloso. Vereda de Socuéllamos, s/n. 13700 Tomelloso, Ciudad Real. Spain

e-mail: alucendo@vodafone.es
Lucendo AJ, García-Manzanares A. Bone mineral density in adult coeliac disease: An updated review. Rev Esp Enferm Dig 2013; 105:154-162.

\section{INTRODUCTION}

A low bone mineral density (BMD) constitutes the first diagnostic criterion for osteoporosis, a skeletal metabolic disease further defined by impaired bone microarchitecture, increased bone fragility and susceptibility to bone fractures. The availability of bone density scan as a non-invasive diagnostic technique uncovered the link between this bone disorder and coeliac disease (CD) relatively few years ago $(1,2)$. By contrast, the association between child osteomalacia and $C D$ has been known since the first descriptions of the latter disease, even before the origin and treatment of CD itself were known (3). Osteomalacia is a disease characterized by low BMD, marked bone deformities and rickets, which, on rare occasions, is part of the initial presentation of CD $(4,5)$.

$\mathrm{CD}$ is a highly prevalent disease (6) that affects around $1 \%$ of the world population according to serology-based screening studies (7). While CD has been traditionally considered a childhood-onset disorders predominantly, it is now conclusively demonstrated that most patients are diagnosed when adults, as also corroborated in our country $(8,9)$, among whom both atypical manifestations and a low suspicion index may delay the diagnosis (10). In fact, most CD sufferers are undiagnosed, and women are more frequently diagnosed than men. Many current CD patients lived with their symptoms for years before diagnosis, and were therefore exposed to the consequences of the disease. Furthermore, osteoporosis presents characteristics similar to those of $C D$ in terms of frequency and underdiagnosis. It has been hypothesized that CD could explain part of the considerable "mixed bag" represented by idiopathic 
osteoporosis $(1,11-13)$ Therefore, a high rate of suspicion among health professionals treating both diseases $(C D$ and osteoporosis) and using their best knowledge could bring many hidden cases to light, with the benefit of accurate and early treatment.

In adult patients, changes in bone mineralization, osteopenia or osteoporosis represent one of the most common complications of $\mathrm{CD}$, and can affect up to $75 \%$ of patients in some series (1) with a prevalence among coeliac sufferers that is double that of the unaffected population in the same age range (11). Despite this, and the many studies on the subject notwithstanding, a description of how CD a primarily digestive disorder- can affect bone metabolism has yet to be fully elucidated.

$\mathrm{CD}$ in itself causes significant deterioration in quality of life (14-16), which is compounded by the presence of osteoporosis and its clinical manifestation as fractures. These and other factors are reasons for physicians to adopt an interventionist stance and try to prevent its occurrence and/or mitigate its impact.

\section{OSTEOPOROSIS: DEFINITION AND GENERAL CONCEPTS}

Osteoporosis is the most common metabolic bone disease. It involves a reduction in bone mass and is responsible for most fractures suffered by adults over 50. It is estimated that 1 in 3 women over 50 in Europe (17) and the United States (18) will suffer an osteoporotic fracture during their lifetimes. Although BMD is considered the major determinant of osteoporosis, there are additional factors that influence bone fragility, which, in recent years, have been brought together under the term "bone quality." These include microarchitecture, the degree of bone turnover, the build-up of lesions or microfractures and the degree of bone mineralization (19).

The World Health Organization establishes different degrees of low bone mass based on bone density scan measurements of any skeletal area in American Caucasian women (20). This strategy establishes a diagnosis of osteoporosis when bone mass values are below -2.5 standard deviations (SD) of peak bone mass (i.e. the maximum BMD value reached by an adult), and osteopenia when

Table I. World Health Organization (WHO) diagnostic criteria for post-menopausal Caucasian women

\begin{tabular}{ll}
\hline Diagnosis & BMD criteria (T-score) \\
\hline Normal & BMD T $>-1$ SD \\
Osteopenia or low bone density & BMD T $<-1$ and $>-2.5$ SD \\
Osteoporosis & BMD T $<-2.5$ SD \\
Severe osteoporosis & BMD T $>-2.5$ SD + fracture
\end{tabular}

T-score: Comparison with BMD value in average reference population; SD: Standard deviation; BMD: Bone mineral density. those values are located between -1 SD and -2.5 SD. Severe or established osteoporosis is that presenting with a BMD less than $-2.5 \mathrm{SD}$ and a current or past fragility fracture $(18,21)$. The results of BMD measurements are expressed as a T-score, which is the number of standard deviations by which BMD measurement differs from bone density measurement in the young population ("peak" BMD) (Table I). Another way of expressing the results is the Z-score, which is obtained by comparing a BMD measurement with reference values for subjects of the same age and gender. It is recommended in some guidelines (22) for men and for premenopausal women.

\section{PREVALENCE OF OSTEOPOROSIS AMONG COELIAC DISEASE PATIENTS}

It is estimated that by the time childhood CD is diagnosed, one-third of affected children have osteoporosis, one-third have osteopenia and only the remaining third retain a normal BMD (12). In any case, once the glutenfree diet (GFD) is instituted, most coeliac children catch up to their height-weight growth curve and accelerate their rate of bone mineralization, so that most achieve normal peak bone mass by the time bone growth is completed. The main problem arises when $\mathrm{CD}$ is diagnosed during adulthood, once bone growth is complete and peak bone mass has been reached. Among these patients, the prevalence of osteoporosis is at least twice that of the unaffected population in the same age range $(11,23)$. More than half of asymptomatic coeliac patients with positive serological and digestive tract markers may have bone disease at the time of diagnosis $(1,13,24-28)$. This even includes those without villous atrophy, that is, at stages 1 and 2 of the Marsh-Oberhuber classification for duodenal lesion.

Prevalence studies of bone mass loss among patients with CD reveal widely variable frequencies $(2,24,29-36)$ (Table II); Valdimarsson et al. carried out a prospective study of 63 adult patients and noted a prevalence of

Table II. Studies of BMD in adult patients with coeliac disease before starting GFD (adapted from Scott, 2000) (31)

\begin{tabular}{lll}
\hline Parameter & $\begin{array}{l}\text { Mean weighted } \\
\text { value }\end{array}$ & $\begin{array}{l}\text { Number of studies } \\
\text { (number of } \\
\text { subjects included) }\end{array}$ \\
\hline Z-score, lumbar spine & -1.3 & $14(490)$ \\
Z-score, hip & -1.1 & $7(239)$ \\
T-score, lumbar spine & -1.7 & $1(86)$ \\
T-score, hip & -1.4 & $1(86)$ \\
$\%$ with lumbar osteoporosis & 26 & $6(212)$ \\
$\%$ with hip osteoporosis & 11 & $3(102)$ \\
$\%$ with lumbar osteopenia & 41 & $4(188)$ \\
$\%$ with hip osteopenia & 43 & $3(102)$ \\
\hline
\end{tabular}


osteoporosis of $22 \%$ in the forearm, $18 \%$ in the hip and $15 \%$ in the lumbar spine (estimated on the basis of Zscores) (37). Bardella et al. only documented low BMD among women diagnosed with CD during adulthood (38). Meyer et al. found low BMD in the lumbar spine in $38 \%$ and in the hip in $44 \%$ of the adult coeliac patients analysed (36). The wide variability in the frequency of low BMD in these studies may be explained by several factors, including the diagnostic criteria for osteoporosis ( $\mathrm{T}$ or Z-score), the measurement method, the skeletal location where the measurement was obtained, patient selection, and whether assessment was performed before or after a GFD was started. In any case, the available data confirm a clearly heightened prevalence of low BMD among coeliac patients compared to the general population, which generally ranges around $40 \%$.

Low BMD has been demonstrated in patients with classic symptoms (14), in sub-clinical cases (39), and even in asymptomatic patients (29). Paradoxically, even greater impairment has been observed among patients without digestive symptoms than among those with classic symptoms (13). Therefore, the type of CD-related symptom does not seem to predict the presence of low BMD, which explains attempts to identify other determinants.

Osteoporosis is therefore a common complication of $\mathrm{CD}$, which suggests that it is appropriate to consider whether or not to screen for CD in patients with idiopathic osteoporosis. Although there is no definitive consensus, the greater weight of opinion is in favour of this strategy (40-43), as the frequency of CD is 10 times higher than expected in patients with osteoporosis; in fact, a similar frequency of $\mathrm{CD}$ among type 1 diabetics already justifies universal screening among these patients (44). Moreover, CD screening through specific antibodies in patients with OS has led to diagnosis of between 4 (45) and 17 (43) times more coeliacs.

Results from studies where results were opposed to screen CD patients for osteoporosis can be explained due to the use of low-sensitivity antibodies; in fact, LegrouxGerot et al. only measured anti-gliadin antibodies, while tissue anti-transglutaminase (AAtTG) was only determined in those with positive titres (46), a strategy that underdiagnoses CD. This same study established the AAtTG positivity threshold at $50 \mathrm{U} / \mathrm{ml}$, well above the $2 \mathrm{U} / \mathrm{ml}$ threshold currently recommended for diagnosing adults (47). Other studies suffer from similar limitations: Mather et al. measured antiendomysial antibodies (48), Lindh et al. antigliadin (45), and the positivity threshold for AAtTG in Laadhar's research was set at $10 \mathrm{U} / \mathrm{ml}$ (42).

\section{AETIOLOGY AND PATHOGENESIS OF LOW BMD IN CD}

The pathogenic mechanisms underlying metabolic bone disease in patients with CD have not been fully elucidated. The origin of osteoporosis in CD has been classically associated with malabsorption caused by intestinal villous atrophy and poor absorption of calcium and vitamin D (49), as well as secondary hyperparathyroidism (50). Low consumption of dairy products (51), failure to ever reach peak theoretical bone mass $(29,52-54)$, higher degree of duodenal injury in biopsies (55), and greater delay in diagnosis (23) have also been directly related to the pathogenesis of low BMD in coeliac patients.

We know that vitamin D deficiency is common among patients with $\mathrm{CD}$, although there are no changes in the expression of vitamin D receptors (56) or a greater number of receptor gene mutations interfering with the metabolism of this vitamin (57) in this population. Restricted milk intake may exacerbate vitamin D deficiency; in fact, co-occurrence of lactose intolerance is common among coeliac patients, and is estimated at $10 \%$, but may increase to $50 \%$ in presence of obvious symptoms of malabsorption (58-61). However, one must bear in mind that diet only provides 5-10\% of required vitamin D (62), with the rest being obtained from exposure to sunlight. Even so, studies of coeliac patients have failed to establish any clear association between vitamin $\mathrm{D}$ levels and bone impairment. This is also the case for other intestinal diseases, such as inflammatory bowel disease (62).

Several authors have suggested that deficits in other fatsoluble vitamins (A, K and E) and even water-soluble vitamins (C, B12, folic acid and B6) or minerals (such as iron, calcium, phosphorus, copper, zinc, boron, fluorine), which are all required for normal bone metabolism $(55,63)$, also result from the intestinal malabsorption exhibited by coeliac patients.

Hyperparathyroidism is another implicated factor; even in patients with normal vitamin D serum levels, high PTH levels have been associated with bone mass loss (50). Indeed, coeliac patients on a GFD frequently exhibit high serum PTH levels (64). Reduced serum levels of IGF-1 (insulin-like growth factor-1 or somatomedin C) (65) constitutes an additional hormonal factor which has been involved in patients with a lower bone mass. This was associated with decreased serum levels of zinc (66), which normalized after introduction a GFD.

Despite the above, the malabsorption theory in and of itself has not been corroborated in some studies (55), while the complex regulation of bone turnover and the effect of the multiple nutritional factors involved, together with the discordant results of various studies, have led to the emergence of new hypotheses for the origin of osteoporosis in $\mathrm{CD}$, such as the link between low BMD and chronic inflammation (67). Indeed, a less well-known function of vitamin $\mathrm{D}$ is its role in the activation of $\mathrm{T}$ lymphocytes that maintain the integrity of intestinal mucosal immunity, prevent infection (68) and regulate protein binding (69). Accordingly, vitamin D deficiency has long been considered a trigger of autoimmune and inflammatory diseases (70).

Chronic inflammation determines changes in bone metabolism via several proinflammatory cytokines, such as tumour necrosis factor alpha $(\mathrm{TNF}-\alpha)$, interleukins 
(IL)-1beta, IL-6 or gamma interferon. TNF-related cytokines include the receptor activator of nuclear factor kappa-B (RANK), its ligand (RANKL), and osteopreotegerin (OPG). RANKL is a key molecule in the regulation of bone metabolism; its genetic expression is induced after activation of $\mathrm{T}$ lymphocytes and it is secreted by these cells. RANKL has proved to be a survival factor whose primary function is activation of osteoclasts, cells involved in bone resorption (71). Overproduction of RANKL is implicated in a variety of degenerative diseases of bone tissue, such as rheumatoid arthritis or psoriatic arthritis, while RANKL gene inactivation in mice produces severe osteopetrosis caused by a massive osteoclast deficit $(72,73)$. Conversely, OPG (osteoprotegerin, "for bone protection") is an osteoclastogenesis-inhibiting protein, which acts as a decoy receptor homologous to RANK, binds to its ligand RANKL, and thereby neutralizes its action (74). OPG production is stimulated in vivo by oestrogens and by the anti-resorptive drug strontium ranelate (75). IL-6 promotes the expression of both RANKL and OPG, and stimulates both osteoblast formation and bone resorption.

Serum levels of RANKL and OPG are high in patients with CD (76), and the relative relationship established between these cytokines is therefore more important than their actual levels; hence, an imbalance in the OPG/RAN$\mathrm{KL}$ ratio has been associated with altered bone turnover in patients with different conditions, including renal osteodystrophy (77), rheumatoid arthritis (78), Cushing's disease (79) and primary biliary cirrhosis (80). The OPG/RANKL ratio is directly associated with IL-6 serum levels (79) and lumbar bone mass (81). Thus, adult women with CD have OPG/RANKL ratios significantly lower than controls despite adherence to a GFD; this correlates with a lower lumbar BMD (82). Although the role of high OPG levels in CD has not been fully elucidated, the available evidence suggests that this is a protective mechanism against other factors that cause bone damage. The mechanisms described as direct activators of osteoclastogenesis and subsequent bone mass loss (83) have recently been recognized as potential contributors to osteoporosis among patients with a range of digestive diseases. In fact, patients with CD and inflammatory bowel disease have similar profiles in terms of expression of bone metabolism regulatory cytokines (84-86).

Finally, the aetiology of osteoporosis in CD of course includes factors shared with the rest of the population (87) (family history, age, menopause, physical activity, smoking), as well as other specific factors such as genetic influence, the above-mentioned vitamin deficiencies, hormonal changes and the inflammatory process itself.

Years of exposure to gluten in the diet before diagnosis do not appear to influence BMD significantly $(29,35$, $36,88,89)$ nor does early menopause (27). Some studies report an inverse relationship between GFD and calcium intake (90). There is little data on the influence of patient sex on BMD, but most studies show no difference in this respect $(27,36,37,91,92)$. Another factor associated with poor bone condition is a low body mass index (BMI) $(14,55,87,93)$. Patients with persistent villous atrophy despite proper adherence to the GFD (refractory CD) are particularly susceptible to osteoporosis, with a prevalence of $58 \%$ compared to the $22 \%$ reported among GFDresponsive patients (93).

\section{DIAGNOSIS OF LOW BONE MINERAL DENSITY IN CD}

All patients in whom there is clinical suspicion of osteoporosis should undergo a thorough history-taking and physical examination so as to identify other risk factors and/or consequences. As for imaging methods, conventional radiography has not proven to be a specific or sensitive method for assessment of changes in bone mass; therefore, osteoporosis studies should be performed using bone density scans. In the case of CD, it has been suggested that all patients diagnosed in adulthood should undergo bone densitometry $(14,94)$, as it is a simple, non-invasive and highly accurate (95) diagnostic method (the margin of error is estimated at only 5-6\%). Its greatest benefit is determining whether there is osteoporosis and the degree of impairment, so that a treatment regimen can be planned. However, some studies, seeing the low risk of bone fracture among coeliac patients, have questioned the utility of routine bone density scan $(31,96)$, as it is considered to have low cost-effectiveness. Other authors suggest using densitometry only in patients with digestive conditions (97), even though this is not a conditioning factor for greater risk (98). In fact, coeliac patients without gastrointestinal symptoms may have low BMD, which increases after start of the GFD (13). Recent studies advocate densitometric assessment in all coeliac patients diagnosed during adulthood who have villous atrophy on duodenal biopsies and/or laboratory values suggestive of malnutrition or malabsorption, regardless of their symptoms (55).

Another issue raised in the literature concerns the optimal timing for bone density scan in coeliac patients -whether at the time of CD diagnosis or after a period of adherence to the GFD. In fact, coeliac children show a great bone recovery capacity after starting a GFD, so no further studies seem to be necessary until their growth period is completed. In any case, the main benefit of BMD testing would be obtained when the introduction of a different treatment rather than the GFD alone are derived from test results.

As development of osteoporosis is determined by multiple risk factors, identifying which of these factors are most relevant, or using a score for the risk of fracture at 10 years, is highly desirable. Markers of bone remodelling (such as the N-terminal telopeptide of procollagen-1, hydroxyproline, and bone alkaline phosphatase) provide additional information on the dynamics of bone turnover that is complementary to densitometry findings. In coeliac patients with osteoporosis, levels of these markers are higher than in coeliacs with normal BMD (55). However, the usefulness 
of their determination in the diagnosis of bone diseases is limited, so measurement is not recommended as part of the routine evaluation of patients with osteoporosis.

\section{BONE FRACTURE RISK IN CD}

Due to the increased prevalence of osteoporosis, coeliac patients have a high risk of fracture, estimated at between 3.5 to 7 times higher than that of the unaffected population of the same age and gender (14). Furthermore, up to one in four adult CD patients have an established history of fractures (99), which produces significant deterioration in quality of life.

As in other aspects of the relationship between $\mathrm{CD}$ and osteoporosis, quantification of fracture risk by different studies shows mixed results. These discrepancies are largely due to the way in which the data were collected -mainly from fracture reports, questionnaires, or hospital admissions. It is therefore possible that the prevalence of fractures (vertebral, hip, and overall) is underestimated in the coeliac population. One of the common issues of fracture risk studies is that they lack proper morphometric assessment of the spine, which underestimates fractures at that level (2), or failure to use validated questionnaires or methods, such as the FRAX $^{\circledast}$ (Fracture Risk Assessment Tool) index proposed by the World Health Organization (100).

To date, nine published studies and one meta-analysis have estimated the incidence or prevalence of bone fractures in the adult coeliac population (31) (Table III). Their heterogeneous methodologies, use of different cut-off points for determination of osteoporosis, and variable diagnostic criteria for $\mathrm{CD}$ translate into significant discrepancies in results. A study conducted in Argentina on 165 coeliac patients retrospectively determined a prevalence of peripheral fractures over 3 times higher than that observed in controls (2). The same study showed that the highest prevalence of fractures in the lumbar spine was only present in patients with "classic symptoms" of CD (101). A retrospective study carried out in the UK showed that $21.3 \%$ of coeliac patients had a history of fractures, compared with only $2.7 \%$ of non-coeliac controls, a highly significant difference quantified as a relative risk (RR) of 7.0 (102). By contrast, other studies with large sample sizes in the same geographical region found no major differences (32). Two further researches in Europe, the first with a large number of patients, reported a slight increase in risk of fracture: a study of approximately 13,000 patients and 65,000 controls in Sweden showed a $2.1 \%$ higher risk (95\%CI: 1.8-2.4) of hip fracture and a $1.4 \%$ higher risk (95\%CI: 1.3-1.5) of any type of fracture among coeliacs (34). A recent study of adult coeliacs in Spain, conducted at the time of diagnosis, used the FRAX ${ }^{\circledast}$ tool to estimate the risk of fracture at 10 years. This showed a moderate risk of fracture among patients with duodenal villous atrophy (Marsh stage III), which was 3.5 times that of patients without villous atrophy (Marsh stage I or II) (55).
Finally, the Olmos et al. meta-analysis (104), which included 21,000 coeliac patients and about 100,000 controls, confirmed a $43 \%$ increase in the prevalence of fractures among coeliacs (8.7vs. $6.1 \%)$.

\section{TREATMENT OF LOW BONE MINERAL DENSITY IN PATIENTS WITH CD}

The first-line treatment for osteoporosis in CD is GFD itself: Many studies have demonstrated its effect on bone density and calcium absorption $(24,26,27,30,35,90-93,105-$ 108). The greatest bone mass gain described in these studies is during the first year $(27,37)$ : GFD leads to a $5 \%$ increase in bone mass after 1 year (1), although this is not enough for bone mass to normalise. In clinical practice conditions, the degree of adherence to the GFD also determines the recovery of bone mass, which is generally estimated at around $30 \%(109,110)$. Furthermore, the recovery rate is higher in young coeliac patients (24) than among adults $(24,37)$, which is largely explained by the fact that $97 \%$ of bone mass is gained in the first two decades of life and full recovery is difficult after this time.

BMD loss associated with paediatric CD responds to GFD continuously and gradually, with almost complete restoration of bone mass after about two years' treatment (111). The earlier the age at which the GFD is started, the better and faster the response (29). In fact, it is estimated that an increase in BMD will only take place if the GFD is started before the age of 25 (49). Proper GFD is so important for bone metabolism that lack of improvement in BMD after its introduction has been associated with persistent duodenal lesions (14).

In addition to the GFD, and in accordance with the NIH consensus statement on the treatment of osteoporosis (18), adequate daily intake of calcium and vitamin D should be ensured, as it is a critical factor for bone mass acquisition and maintenance. Untreated adult coeliac patients have shown a $45 \%$ reduction in calcium absorption followed by an improvement of $52 \%$ after 6 months of GFD adherence (112). Regarding vitamin $\mathrm{D}$, at the time of diagnosis, less than $5 \%$ of Spanish adult CD patients had normal serum levels (55). A daily intake of 1,200-1,500 mg calcium and $800 \mathrm{U}$ vitamin $\mathrm{D}$ is recommended, and as in all other forms of osteoporosis, this should be supplemented with medications. Adherence to drug therapy, as to the GFD, is a crucial aspect of treatment, so patients must be kept motivated. In fact, these patients will most commonly abandon treatment with calcium and vitamin $\mathrm{D}$, as it must be taken daily, while hormonal therapy and bisphosphonates (which are administered weekly) are usually adhered to correctly (113). Drug treatment would be indicated for patients who do not achieve bone mass recovery goals, and would not differ from that established for other causes of osteoporosis, with bisphosphonates being the recommended first-line therapy. However, the literature is lacking in data on the specific effect of bisphosphonates on CD-associated osteoporosis. 


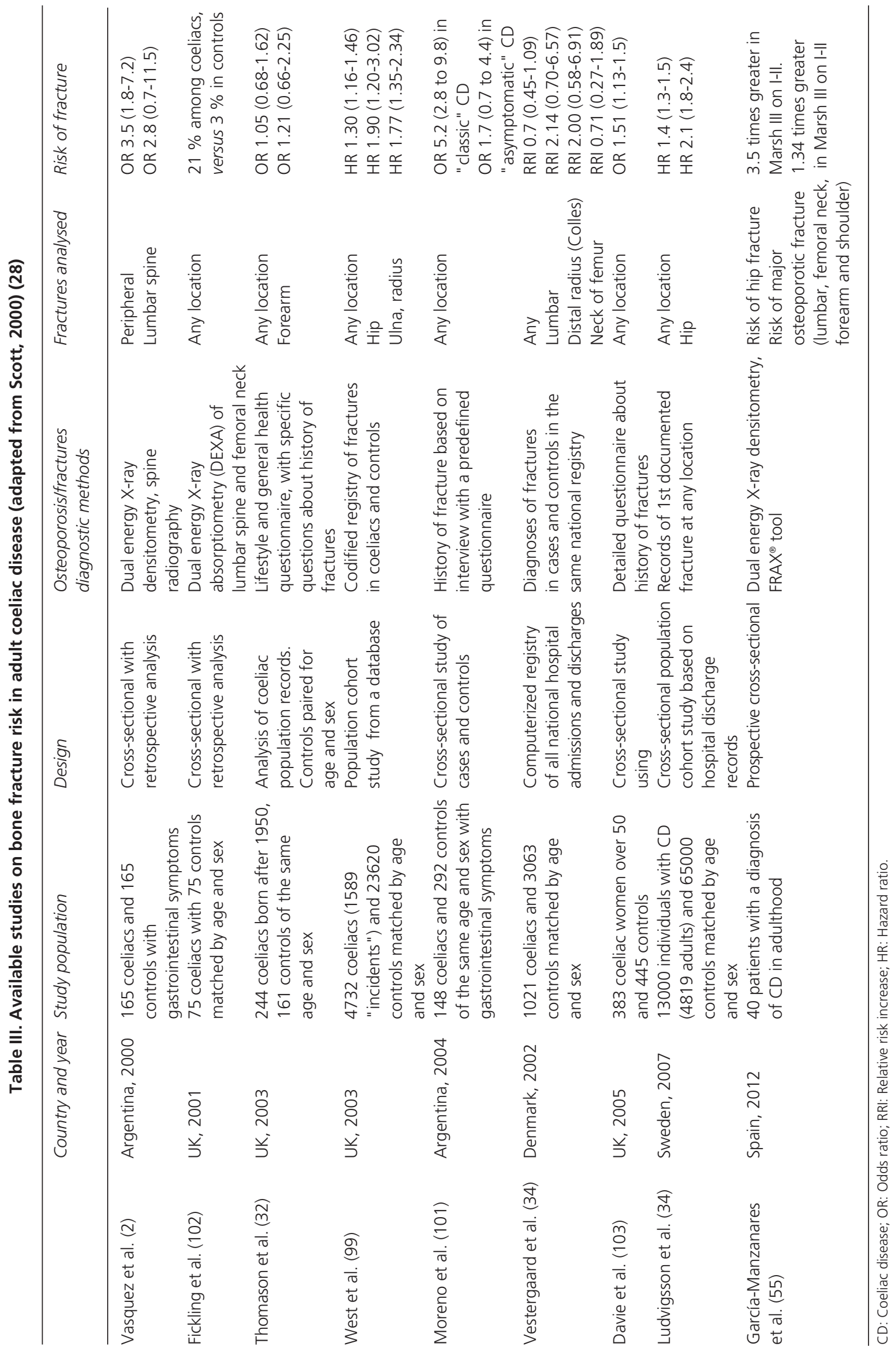




\section{CONCLUSIONS}

$\mathrm{CD}$ has been associated with low BMD since its very first descriptions. Osteomalacia in children with $\mathrm{CD}$ is now an exceptionally rare finding; unfortunately, the same cannot be said for osteoporosis and osteopenia, which occur in $40 \%$ of patients diagnosed in adulthood and determine a variable increase in the risk of bone fracture, leading to lower quality of life. Changes in the epidemiology of CD make low BMD screening by bone density scans more relevant for adult coeliacs. Subjects with villous atrophy or laboratory values suggestive of malnutrition at the time of $\mathrm{CD}$ diagnosis may derive greater benefit from bone density scan.

The gluten-free diet is also the basis of low BMD treatment among coeliacs, and is sufficient in younger patients. In adults with low bone mass, however, it must be supplemented with calcium and vitamin D. Although specific studies are lacking, bisphosphonates might also provide an effective first line of treatment for adult coeliac patients with osteoporosis.

\section{REFERENCES}

1. Corazza GR, Di SM, Maurino E, Bai JC. Bones in coeliac disease: diagnosis and treatment. Best Pract Res Clin Gastroenterol 2005; 19:453-65.

2. Vasquez H, Mazure R, Gonzalez D, Flores D, Pedreira S, Niveloni S, et al. Risk of fractures in celiac disease patients: a cross-sectional, casecontrol study. Am J Gastroenterol 2000;95:183-9.

3. Salvesen HA, Boe J. Osteomalacia in sprue. Acta Med Scand 1953; 146:290-9.

4. Basu RA, Elmer K, Babu A, Kelly CA. Coeliac disease can still present with osteomalacia! Rheumatology (Oxford) 2000;39:335-6.

5. Rabelink NM, Westgeest HM, Bravenboer N, Jacobs MA, Lips P. Bone pain and extremely low bone mineral density due to severe vitamin D deficiency in celiac disease. Arch Osteoporos 2011;6:209-13.

6. Rodrigo-Sáez L, Fuentes-Álvarez D, Álvarez-Mieres N, Niño-García P, de Francisco García R, Riestra-Menendez S. Enfermedad Celiaca en el 2009. RAPD Online 2009;32:339-57.

7. Reilly NR, Green PH. Epidemiology and clinical presentations of celiac disease. Semin Immunopathol 2012;34:473-8.

8. Lucendo AJ, García-Manzanares A, Arias A, Fuentes D, Álvarez N, Pérez I, et al. Coeliac Disease in the 21st Century: No Longer "Kids' Stuff"' Gastroenterology Research 2011;4:268-76.

9. Fernández A, González L, De la Fuente J. Celiac disease: Clinical features in adult populations. Rev Esp Enferm Dig 2010;102:466-71.

10. Rodrigo-Sáez L, Fuentes-Álvarez D, Pérez-Martínez I, ÁlvarezMieres N, Niño-García P, de-Francisco-García R, et al. Differences between pediatric and adult celiac disease. Rev Esp Enferm Dig 2011;103:238-44.

11. Sundar N, Crimmins R, Swift G. Clinical presentation and incidence of complications in patients with coeliac disease diagnosed by relative screening. Postgrad Med J 2007;83:273-6.

12. Goddard CJ, Gillett HR. Complications of coeliac disease: are all patients at risk? Postgrad Med J 2006;82:705-12

13. Mustalahti K, Collin P, Sievanen H, Salmi J, Maki M. Osteopenia in patients with clinically silent coeliac disease warrants screening. Lancet 1999;354:744-5.

14. Walters JR, Banks LM, Butcher GP, Fowler CR. Detection of low bone mineral density by dual energy $\mathrm{X}$ ray absorptiometry in unsuspected suboptimally treated coeliac disease. Gut 1995;37:220-4.

15. Dorn SD, Hernandez L, Minaya MT, Morris CB, Hu Y, Leserman J, et al. The development and validation of a new coeliac disease quality of life survey (CD-QOL). Aliment Pharmacol Ther 2010;31:666-75.
16. de Lorenzo CM, Xikota JC, Wayhs MC, Nassar SM, de Souza Pires MM. Evaluation of the quality of life of children with celiac disease and their parents: a case-control study. Qual Life Res 2012;21:77-85.

17. Gullberg B, Johnell O, Kanis JA. World-wide projections for hip fracture. Osteoporos Int 1997;7:407-13.

18. Osteoporosis prevention, diagnosis, and therapy. NIH Consens Statement 2000;17:1-45.

19. Sambrook P, Cooper C. Osteoporosis. Lancet 2006;367:2010-8.

20. Sosa HM, Diaz CM, Diez PA, Gomez AC, Gonzalez MJ, Farrerons MJ, et al. Guide for the prevention and treatment of glucocorticoidinduced osteoporosis of the Spanish Society of Internal Medicine. Rev Clin Esp 2008;208:33-45.

21. Consensus development conference: Diagnosis, prophylaxis, and treatment of osteoporosis. Am J Med 1993;94:646-50.

22. Khan AA, Bachrach L, Brown JP, Hanley DA, Josse RG, Kendler DL, et al. Standards and guidelines for performing central dual-energy $\mathrm{X}$ ray absorptiometry in premenopausal women, men, and children. J Clin Densitom 2004;7:51-64.

23. Younes M, Ben YH, Safer L, Fadoua H, Zrour S, Bejia I, et al. Prevalence of bone loss in adult celiac disease and associated factors: a control case study. Tunis Med 2012;90:129-35.

24. Mora S, Weber G, Barera G, Bellini A, Pasolini D, Prinster C, et al. Effect of gluten-free diet on bone mineral content in growing patients with celiac disease. Am J Clin Nutr 1993;57:224-8.

25. Corazza GR, Valentini RA, Andreani ML, D'Anchino M, Leva MT, Ginaldi L, et al. Subclinical coeliac disease is a frequent cause of irondeficiency anaemia. Scand J Gastroenterol 1995;30:153-6.

26. Caraceni MP, Molteni N, Bardella MT, Ortolani S, Nogara A, Bianchi PA. Bone and mineral metabolism in adult celiac disease. Am J Gastroenterol 1988;83:274-7.

27. McFarlane XA, Bhalla AK, Reeves DE, Morgan LM, Robertson DA. Osteoporosis in treated adult coeliac disease. Gut 1995;36:710-4.

28. Gonzalez D, Mazure R, Mautalen C, Vazquez H, Bai J. Body composition and bone mineral density in untreated and treated patients with celiac disease. Bone 1995;16:231-4.

29. Mazure R, Vazquez H, Gonzalez D, Mautalen C, Pedreira S, Boerr L, et al. Bone mineral affection in asymptomatic adult patients with celiac disease. Am J Gastroenterol 1994;89:2130-4.

30. Bai JC, Gonzalez D, Mautalen C, Mazure R, Pedreira S, Vazquez H, et al. Long-term effect of gluten restriction on bone mineral density of patients with coeliac disease. Aliment Pharmacol Ther 1997;11: 157-64.

31. Scott EM, Gaywood I, Scott BB. Guidelines for osteoporosis in coeliac disease and inflammatory bowel disease. British Society of Gastroenterology. Gut 2000;46(Supl. 1):i1-i8.

32. Thomason K, West J, Logan RF, Coupland C, Holmes GK. Fracture experience of patients with coeliac disease: A population based survey. Gut 2003;52:518-22.

33. Vestergaard P, Mosekilde L. Fracture risk in patients with celiac disease, Crohn's disease, and ulcerative colitis: A nationwide follow-up study of 16,416 patients in Denmark. Am J Epidemiol 2002;156:1-10.

34. Ludvigsson JF, Michaelsson K, Ekbom A, Montgomery SM. Coeliac disease and the risk of fractures - A general population-based cohort study. Aliment Pharmacol Ther 2007;25:273-85.

35. Lewis NR, Scott BB. Should patients with coeliac disease have their bone mineral density measured? Eur J Gastroenterol Hepatol 2005; 17:1065-70.

36. Meyer D, Stavropolous S, Diamond B, Shane E, Green PH. Osteoporosis in a north American adult population with celiac disease. Am J Gastroenterol 2001;96:112-9.

37. Valdimarsson T, Lofman O, Toss G, Strom M. Reversal of osteopenia with diet in adult coeliac disease. Gut 1996;38:322-7.

38. Bardella MT, Fredella C, Prampolini L, Molteni N, Giunta AM, Bianchi PA. Body composition and dietary intakes in adult celiac disease patients consuming a strict gluten-free diet. Am J Clin Nutr 2000; 72:937-9.

39. Corazza GR, Di SA, Cecchetti L, Jorizzo RA, Di SM, Minguzzi L, et al. Influence of pattern of clinical presentation and of gluten-free diet on bone mass and metabolism in adult coeliac disease. Bone 1996; 18:525-30.

40. Drummond FJ, Annis P, O'Sullivan K, Wynne F, Daly M, Shanahan $\mathrm{F}$, et al. Screening for asymptomatic celiac disease among patients referred for bone densitometry measurement. Bone 2003;33:970-4. 
41. Gonzalez D, Sugai E, Gomez JC, Oliveri MB, Gomez AC, Vega E, et al. Is it necessary to screen for celiac disease in postmenopausal osteoporotic women? Calcif Tissue Int 2002;71:141-4.

42. Laadhar L, Masmoudi S, Bahlous A, Zitouni M, Sahli H, Kallel-Sellami $\mathrm{M}$, et al. Is screening for celiac disease in osteoporotic post-menopausal women necessary? Joint Bone Spine 2007;74:510-1.

43. Stenson WF, Newberry R, Lorenz R, Baldus C, Civitelli R. Increased prevalence of celiac disease and need for routine screening among patients with osteoporosis. Arch Intern Med 2005;165:393-9.

44. Introduction: The American Diabetes Association's (ADA) evidencebased practice guidelines, standards, and related recommendations and documents for diabetes care. Diabetes Care 2012;35(Supl. 1):S1-S2.

45. Lindh E, Ljunghall S, Larsson K, Lavo B. Screening for antibodies against gliadin in patients with osteoporosis. J Intern Med 1992; 231:403-6.

46. Legroux-Gerot I, Leloire O, Blanckaert F, Tonnel F, Grardel B, Ducrocq JL, et al. Screening for celiac disease in patients with osteoporosis. Joint Bone Spine 2009;76:162-5.

47. Santaolalla R, Fernandez-Banares F, Rodriguez R, Alsina M, Rosinach M, Marine M, et al. Diagnostic value of duodenal antitissue transglutaminase antibodies in gluten-sensitive enteropathy. Aliment Pharmacol Ther 2008;27:820-9.

48. Mather KJ, Meddings JB, Beck PL, Scott RB, Hanley DA. Prevalence of IgA-antiendomysial antibody in asymptomatic low bone mineral density. Am J Gastroenterol 2001;96:120-5.

49. Ciacci C, Maurelli L, Klain M, Savino G, Salvatore M, Mazzacca G, et al. Effects of dietary treatment on bone mineral density in adults with celiac disease: Factors predicting response. Am J Gastroenterol 1997;92:992-6.

50. Selby PL, Davies M, Adams JE, Mawer EB. Bone loss in celiac disease is related to secondary hyperparathyroidism. J Bone Miner Res 1999; 14:652-7.

51. Kinsey L, Burden ST, Bannerman E. A dietary survey to determine if patients with coeliac disease are meeting current healthy eating guidelines and how their diet compares to that of the British general population. Eur J Clin Nutr 2008;62:1333-42.

52. Bernstein CN, Leslie WD. The pathophysiology of bone disease in gastrointestinal disease. Eur J Gastroenterol Hepatol 2003;15:857-64.

53. Fisher AA, Davis MW, Budge MM. Should we screen adults with osteoporotic fractures for coeliac disease? Gut 2004;53:154-5.

54. Jatla M, Zemel BS, Bierly P, Verma R. Bone mineral content deficits of the spine and whole body in children at time of diagnosis with celiac disease. Am J Clin Nutr 2009;48:175-80.

55. Garcia-Manzanares A, Tenias JM, Lucendo AJ. Bone mineral density directly correlates with duodenal Marsh stage in newly diagnosed adult celiac patients. Scand J Gastroenterol 2012;8-9:927-36.

56. Colston KW, Mackay AG, Finlayson C, Wu JC, Maxwell JD. Localisation of vitamin $\mathrm{D}$ receptor in normal human duodenum and in patients with coeliac disease. Gut 1994;35:1219-25.

57. Vogelsang H, Suk EK, Janisiw M, Stain C, Mayr WR, Panzer S. Calcaneal ultrasound attenuation and vitamin-D-receptor genotypes in celiac disease. Scand J Gastroenterol 2000;35:172-6.

58. Garcia-Manzanares A, Lucendo AJ. Nutritional and dietary aspects of celiac disease. Nutr Clin Pract 2011;26:163-73.

59. Ojetti V, Nucera G, Migneco A, Gabrielli M, Lauritano C, Danese S, et al. High prevalence of celiac disease in patients with lactose intolerance. Digestion 2005;71:106-10.

60. Bode S, Gudmand-Hoyer E. Incidence and clinical significance of lactose malabsorption in adult coeliac disease. Scand J Gastroenterol 1988;23:484-8

61. Annibale B, Severi C, Chistolini A, Antonelli G, Lahner E, Marcheggiano A, et al. Efficacy of gluten-free diet alone on recovery from iron deficiency anemia in adult celiac patients. Am J Gastroenterol 2001;96:132-7.

62. Jahnsen J, Falch JA, Mowinckel P, Aadland E. Vitamin D status, parathyroid hormone and bone mineral density in patients with inflammatory bowel disease. Scand J Gastroenterol 2002;37:192-9.

63. Stazi AV, Trecca A, Trinti B. Osteoporosis in celiac disease and in endocrine and reproductive disorders. World J Gastroenterol 2008; 14:498-505.

64. Lemieux B, Boivin M, Brossard JH, Lepage R, Picard D, Rousseau L, et al. Normal parathyroid function with decreased bone mineral density in treated celiac disease. Can J Gastroenterol 2001;15:302-7.
65. Valdimarsson T, Arnqvist HJ, Toss G, Jarnerot G, Nystrom F, Strom M Low circulating insulin-like growth factor I in coeliac disease and its relation to bone mineral density. Scand J Gastroenterol 1999;34:904-8.

66. Jameson S. Coeliac disease, insulin-like growth factor, bone mineral density, and zinc. Scand J Gastroenterol 2000;35:894-6.

67. Bianchi ML, Bardella MT. Bone in celiac disease. Osteoporos Int 2008;19:1705-16.

68. Sun J. Vitamin D and mucosal immune function. Curr Opin Gastroenterol 2010;26:591-5.

69. Kong J, Zhang Z, Musch MW, Ning G, Sun J, Hart J, et al. Novel role of the vitamin $\mathrm{D}$ receptor in maintaining the integrity of the intestinal mucosal barrier. Am J Physiol Gastrointest Liver Physiol 2008;294: G208-16.

70. Zittermann A. Vitamin D in preventive medicine: are we ignoring the evidence? Br J Nutr 2003;89:552-72.

71. Buckley KA, Fraser WD. Receptor activator for nuclear factor kappaB ligand and osteoprotegerin: regulators of bone physiology and immune responses/potential therapeutic agents and biochemical markers. Ann Clin Biochem 2002;39:551-6.

72. McClung M. Role of RANKL inhibition in osteoporosis. Arthritis Res Ther 2007;9(Supl. 1):S3.

73. Yogo K, Ishida-Kitagawa N, Takeya T. Negative autoregulation of RANKL and c-Src signaling in osteoclasts. J Bone Miner Metab 2007;25:205-10.

74. Simonet WS, Lacey DL, Dunstan CR, Kelley M, Chang MS, Luthy R, et al. Osteoprotegerin: A novel secreted protein involved in the regulation of bone density. Cell 1997;89:309-19.

75. Hofbauer LC, Khosla S, Dunstan CR, Lacey DL, Spelsberg TC, Riggs BL. Estrogen stimulates gene expression and protein production of osteoprotegerin in human osteoblastic cells. Endocrinology 1999;140: 4367-70.

76. Taranta A, Fortunati D, Longo M, Rucci N, Iacomino E, Aliberti F, et al. Imbalance of osteoclastogenesis-regulating factors in patients with celiac disease. J Bone Miner Res 2004;19:1112-21.

77. Coen G, Ballanti P, Balducci A, Calabria S, Fischer MS, Jankovic L, et al. Serum osteoprotegerin and renal osteodystrophy. Nephrol Dial Transplant 2002;17:233-8.

78. Feuerherm AJ, Borset M, Seidel C, Sundan A, Leistad L, Ostensen M, et al. Elevated levels of osteoprotegerin (OPG) and hepatocyte growth factor (HGF) in rheumatoid arthritis. Scand J Rheumatol 2001;30:229-34.

79. Ueland T, Bollerslev J, Godang K, Muller F, Froland SS, Aukrust P. Increased serum osteoprotegerin in disorders characterized by persistent immune activation or glucocorticoid excess--possible role in bone homeostasis. Eur J Endocrinol 2001;145:685-90.

80. Szalay F, Hegedus D, Lakatos PL, Tornai I, Bajnok E, Dunkel K, et al. High serum osteoprotegerin and low RANKL in primary biliary cirrhosis. J Hepatol 2003;38:395-400.

81. McCormick RK. Osteoporosis: Integrating biomarkers and other diagnostic correlates into the management of bone fragility. Altern Med Rev 2007;12:113-45.

82. Fiore CE, Pennisi P, Ferro G, Ximenes B, Privitelli L, Mangiafico RA, et al. Altered osteoprotegerin/RANKL ratio and low bone mineral density in celiac patients on long-term treatment with gluten-free diet. Horm Metab Res 2006;38:417-22.

83. Rodriguez-Bores L, Barahona-Garrido J, Yamamoto-Furusho JK. Basic and clinical aspects of osteoporosis in inflammatory bowel disease. World J Gastroenterol 2007;13:6156-65.

84. Tilg H, Moschen AR, Kaser A, Pines A, Dotan I. Gut, inflammation and osteoporosis: basic and clinical concepts. Gut 2008;57:684-94.

85. Miheller P, Muzes G, Racz K, Blazovits A, Lakatos P, Herszenyi L, et al. Changes of OPG and RANKL concentrations in Crohn's disease after infliximab therapy. Inflamm Bowel Dis 2007;13:1379-84.

86. Garcia-Manzanares A, Alvarez-Hernandez J, Pelaez N. Soporte nutricional en la enfermedad inflamatoria intestinal. En: Bellido Guerrero D, De Luis Román DA editores. Manual de nutrición y metabolismo. Madrid: Díaz de Santos; 2006. p. 333-48.

87. Di SM, Veneto G, Corrao G, Corazza GR. Role of lifestyle factors in the pathogenesis of osteopenia in adult coeliac disease: a multivariate analysis. Eur J Gastroenterol Hepatol 2000;12:1195-9.

88. Mautalen C, Gonzalez D, Mazure R, Vazquez H, Lorenzetti MP, Maurino $\mathrm{E}$, et al. Effect of treatment on bone mass, mineral metabolism, and body composition in untreated celiac disease patients. Am J Gastroenterol 1997;92:313-8. 
89. Di SM, Jorizzo RA, Veneto G, Cecchetti L, Gasbarrini G, Corazza GR. Bone mass and metabolism in dermatitis herpetiformis. Dig Dis Sci 1999;44:2139-43

90. Pazianas M, Butcher GP, Subhani JM, Finch PJ, Ang L, Collins C, et al. Calcium absorption and bone mineral density in celiacs after long term treatment with gluten-free diet and adequate calcium intake. Osteoporos Int 2005; 16:56-63.

91. Kemppainen T, Kroger H, Janatuinen E, Arnala I, Kosma VM, Pikkarainen $\mathrm{P}$, et al. Osteoporosis in adult patients with celiac disease. Bone 1999;24:249-55.

92. Sategna-Guidetti C, Grosso SB, Grosso S, Mengozzi G, Aimo G, Zaccaria $\mathrm{T}$, et al. The effects of 1-year gluten withdrawal on bone mass, bone metabolism and nutritional status in newly-diagnosed adult coeliac disease patients. Aliment Pharmacol Ther 2000;14:35-43.

93. Kaukinen K, Peraaho M, Lindfors K, Partanen J, Woolley N, Pikkarainen $\mathrm{P}$, et al. Persistent small bowel mucosal villous atrophy without symptoms in coeliac disease. Aliment Pharmacol Ther 2007; 25:1237-45

94. American Gastroenterological Association medical position statement: Guidelines on osteoporosis in gastrointestinal diseases. Gastroenterology 2003;124:791-4.

95. Svendsen OL, Hassager C, Skodt V, Christiansen C. Impact of soft tissue on in vivo accuracy of bone mineral measurements in the spine, hip, and forearm: A human cadaver study. J Bone Miner Res 1995;10:868-73.

96. Murray JA, Van DC, Plevak MF, Dierkhising RA, Zinsmeister AR, Melton LJ, III. Trends in the identification and clinical features of celiac disease in a North American community, 1950-2001. Clin Gastroenterol Hepatol 2003;1:19-27.

97. Reyes GR, Jodar GE, Garcia MA, Romero MM, Gomez Saez JM, Luque FI, et al. Clinical practice guidelines for evaluation and treatment of osteoporosis associated to endocrine and nutritional conditions. Endocrinol Nutr 2012;59:174-96.

98. Cellier C, Flobert C, Cormier C, Roux C, Schmitz J. Severe osteopenia in symptom-free adults with a childhood diagnosis of coeliac disease. Lancet 2000;355:806.

99. West J, Logan RF, Card TR, Smith C, Hubbard R. Fracture risk in people with celiac disease: a population-based cohort study. Gastroenterology 2003;125:429-36.
100. Kanis JA, Johnell O, Oden A, Johansson H, McCloskey E. FRAX and the assessment of fracture probability in men and women from the UK. Osteoporos Int 2008;19:385-97.

101. Moreno ML, Vazquez H, Mazure R, Smecuol E, Niveloni S, Pedreira $\mathrm{S}$, et al. Stratification of bone fracture risk in patients with celiac disease. Clin Gastroenterol Hepatol 2004;2:127-34.

102. Fickling WE, McFarlane XA, Bhalla AK, Robertson DA. The clinical impact of metabolic bone disease in coeliac disease. Postgrad Med J 2001;77:33-6.

103. Davie MW, Gaywood I, George E, Jones PW, Masud T, Price T, et al Excess non-spine fractures in women over 50 years with celiac disease: A cross-sectional, questionnaire-based study. Osteoporos Int 2005; $16: 1150-5$

104. Olmos M, Antelo M, Vazquez H, Smecuol E, Maurino E, Bai JC. Systematic review and meta-analysis of observational studies on the prevalence of fractures in coeliac disease. Dig Liver Dis 2008:40:46-53.

105. Corazza GR, Di SA, Cecchetti L, Tarozzi C, Corrao G, Bernardi M, Gasbarrini G. Bone mass and metabolism in patients with celiac disease. Gastroenterology 1995;109:122-8.

106. Valdimarsson T, Toss G, Lofman O, Strom M. Three years' follow-up of bone density in adult coeliac disease: Significance of secondary hyperparathyroidism. Scand J Gastroenterol 2000;35:274-80.

107. McFarlane XA, Bhalla AK, Robertson DA. Effect of a gluten free diet on osteopenia in adults with newly diagnosed coeliac disease. Gut 1996;39:180-4

108. Molteni N, Bardella MT, Vezzoli G, Pozzoli E, Bianchi P. Intestinal calcium absorption as shown by stable strontium test in celiac disease before and after gluten-free diet. Am J Gastroenterol 1995;90:2025-8.

109. Green PH, Jabri B. Coeliac disease. Lancet 2003;362:383-91.

110. Alaedini A, Green PH. Narrative review: Celiac disease: Understanding a complex autoimmune disorder. Ann Intern Med 2005;142:289-98.

111. Mora S, Barera G, Ricotti A, Weber G, Bianchi C, Chiumello G. Reversal of low bone density with a gluten-free diet in children and adolescents with celiac disease. Am J Clin Nutr 1998:67:477-81.

112. Ciacci C, Cirillo M, Mellone M, Basile F, Mazzacca G, De Santo NG. Hypocalciuria in overt and subclinical celiac disease. Am J Gastroenterol 1995;90:1480-4.

113. Rossini M, Bianchi G, Di MO, Giannini S, Minisola S, Sinigaglia L, et al. Determinants of adherence to osteoporosis treatment in clinical practice. Osteoporos Int 2006;17:914-21. 